\title{
História
}

\section{Entrevista com Sérgio Antônio da Silva Leite}

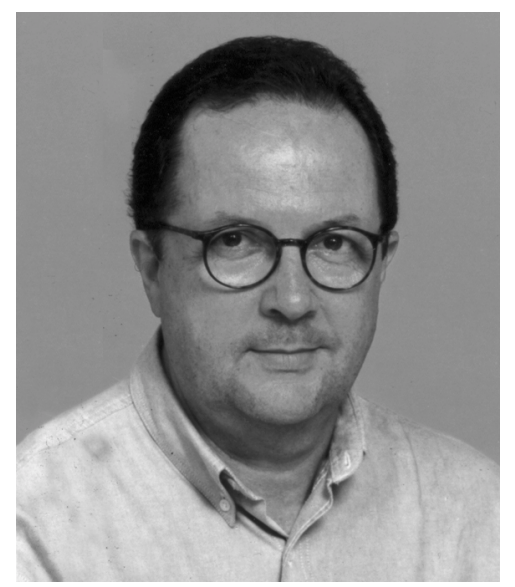

Entrevistadora: Ana Maria Falcão de Aragão Sadalla

SÉRGIO ANTÔNIO DA SILVA LEITE é doutor em Psicologia. Coerência é a palavra que melhor expressa a relação que existe entre o pensamento e as ações do professor e psicólogo Sérgio Leite. Toda a sua trajetória profissional tem sido marcada por um grande envolvimento com a escola pública de qualidade, com a formação de psicólogos e professores que tenham fundamentalmente um compromisso social. Desde os tempos de aluno do antigo Colégio Estadual Culto à Ciência, de Campinas/SP, o Prof. Sérgio tem uma história de militância social e política, orientada para a transformação da sociedade. Constituindo-se como um profissional, cuja crença é marcada pela busca de caminhos para transformar a sociedade, tem demonstrado que não é suficiente fazer a análise e a crítica, mas buscar caminhos de intervenção, preferencialmente coletivos, envolvendo cada vez mais e mais pessoas, mesmo quando isto ocorre em uma época em que a coletividade e a justiça social não são respeitadas, tal como acontecia no período da repressão dos direitos individuais, aqui no Brasil. Seu percurso de atuação profissional demonstra que as concepções teóricas cotejadas são passíveis de transformação, desde que acompanhem o caminhar histórico da revisão de concepções, o que ocorreu com ele em relação à conceituação de leitura e escrita, por exemplo. Formouse em Psicologia pela Pontifícia Universidade Católica de Campinas, em 1971, fez Mestrado em Psicologia Experimental, em 1976 e, em 1980, concluiu o Doutorado em Psicologia, ambos na Universidade de São Paulo. Atualmente é docente do Departamento de Psicologia Educacional da Faculdade de Educação da Unicamp. A coerência, inicialmente referida, é demonstrada também na relação que estabelece com alunos - de graduação e pós - e orientandos, revelada, até mesmo, na congruência com a temática sobre a qual tem atualmente se debruçado: a dimensão afetiva no processo ensino-aprendizagem.

Ana: Quando você escolheu fazer o curso de Psicologia, já havia também uma decisão sobre a área de atuação?

Sérgio Leite: A minha resolução de fazer Psicologia foi tomada no 1o colegial no Culto à Ciência (em Campinas - SP); fiz um teste vocacional e deu que minha área era Humanas. Mas, na verdade, eu já tinha uma 
história muito forte de envolvimento político e com a própria Educação: era militante na ação católica, um movimento da Igreja progressista, de forte conotação política, em que entrei quando estava na $2^{\text {a }}$ série do ginásio, o que acabou reforçando meu encaminhamento para esta área. E eu decidi ser psicólogo; é compreensível que, na época, eu queria ser psicanalista, com divã e tudo mais... Era a perspectiva de ajuda ao próximo... Mas eu, de alguma forma, sempre me liguei na Educação. Eu terminei o colegial tendo sido um ótimo aluno em Português e, quando eu entrei na PUC de Campinas, para fazer a faculdade, enfrentei um problema sério: a minha família não era rica, ao contrário, e para pagar a faculdade tive que trabalhar. Por ter sido o primeiro colocado no vestibular para Psicologia, em 1967, recebi bolsa integral da Universidade para cursar o primeiro ano, mas a partir daí, tinha que arcar com as despesas. Surgiu, então, a oportunidade de ministrar aulas de Português, em um recém-criado cursinho de Madureza (Supletivo), cujos alunos eram operários e jovens com história de repetência em outras escolas de Campinas. Esta foi uma das melhores experiências que eu vivi; tinha um padrão de ensino excelente e o corpo docente era muito envolvido politicamente com a questão da Educação. Na realidade, eram ex-companheiros do movimento estudantil que, após a revolução de 64, não tinham muitas opções de trabalho e formaram esse cursinho. Durante todo o curso de Psicologia eu fui professor, tanto no curso supletivo como, mais tarde, em cursos pré-vestibular, sempre ministrando a disciplina de Português: eu fiquei expert em análise sintática, fazendo análise até de Os Lusíadas, de Camões!! Assim, eu fui me constituindo enquanto professor nesse processo; aprendi muito nesse período do cursinho, porque além de ter sido uma experiência incrível, você tinha que aprender a ser um professor eficiente, o que era avaliado pelo aprendizado dos alunos, demonstrado nos exames seletivos.

\section{Ana: Mas e a idéia da psicanálise e do divã?}

Sérgio Leite: Na faculdade, durante o $1^{\circ}$ ano, a idéia era essa, pois só comecei a conhecer a Psicologia depois que ingressei no curso. Aí eu comecei a ver que a Psicologia tinha muito mais possibilidades, além da minha ingênua visão inicial. Quando eu me formei, já queria dar aula, ser professor, e a minha opção conduziu-me diretamente para a Universidade. Em 1972, recémformado, fui para a Universidade de Mogi das Cruzes
(UMC), indicado pelo ex-professor e amigo Sigmar Malvezzi e já comecei trabalhando com Psicologia Escolar. Na época, também era psicólogo da APAE de Botucatu/SP, mas, como entrei na pós-graduação da USP, tive que deixar o trabalho nesta entidade. Minha dissertação de Mestrado, em 1976, foi sobre treinamento de professor. Hoje, vejo que minha vida profissional pode ser dividida em duas etapas: a primeira centrada em Mogi das Cruzes; a segunda centrada na Unicamp.

\section{Ana: Como foi esta época de Mogi?}

Sérgio Leite: Na época, era um curso muito forte, em virtude do ótimo corpo docente. As primeiras turmas formadas na UMC de Mogi foram de excelente qualidade, sendo que quase todos fizeram carreira nas suas áreas. Eu entrei em 1972, para a área de Escolar, ministrando aulas para o 4ํano de Psicologia e, já no ano seguinte, assumi a coordenação do setor dos estágios em Psicologia Escolar, no 5ํ ano. Com outros colegas ${ }^{1}$, montamos uma equipe inicial, cujo objetivo foi criar, na Universidade, um setor de prestação de serviços para a comunidade. Montamos uma área de escolar que, naquela época, anos setenta, era um projeto avançado: atendíamos pré-escolas, APAE, creches, professores da rede de $1^{\underline{a}}$ a $4^{a}$, coordenadores, etc. Cada setor correspondia a uma subárea de estágio, com um professor responsável, cujo projeto podia ser o atendimento a uma escola, ou realização de pesquisa, ou um curso de treinamento, etc.; enfim, o aluno envolvia-se numa prática efetiva. Para isso, nós fizemos um convênio com a DRE (Divisão Regional de Ensino) de Mogi das Cruzes, e, por meio dela, tivemos acesso à rede estadual e a todas as instituições da região, como orfanatos, creches, APAE, pré-escolas, etc... Eu fui coordenar o trabalho junto ao ensino de 1 o grau; fui para a escola e me deparei com o quadro grave de fracasso escolar nas primeiras séries, que nós tivemos que enfrentar. Mogi era a região vice-campeã do Estado nos índices de repetência e evasão nas primeiras séries. Aí eu fiquei, praticamente, durante os quase 15 anos em que estive na UMC, trabalhando com esse problema. Tive parcerias excelentes na rede; formamos uma equipe na Divisão Regional de Ensino de Mogi e organizamos o PROLESTE $^{2}$, que foi um projeto que conseguiu realmente reverter o quadro de fracasso, pelo menos nesta fase da $1^{\underline{a}}$ a $3^{3}$ série, enquanto esteve implantado. ${ }^{3}$ Este foi um período de ouro na minha vida acadêmica e profissional! O PROLESTE, aliás, foi o tema da minha 
tese de doutorado, defendida em 1980, na USP. Devo registrar também que minha relação com o Instituto de Psicologia da UMC foi intensa, durante o período em que lá trabalhei, chegando a exercer a função de diretor durante um período de três anos.

Ana: A partir daí, então, sua trajetória sempre teve uma inserção na rede pública?

Sérgio Leite: Sempre, sempre; a rede pública sempre esteve na minha vida profissional. Mas muitos dos meus projetos foram interrompidos por crises políticas e/ou institucionais; no caso do PROLESTE, foi a mudança no governo do Estado, no início dos anos oitenta, com o processo de redemocratização do país. Os novos gestores praticamente zeraram todo o trabalho na rede de ensino público sem o devido cuidado de avaliar o que estava ocorrendo e funcionando. Mas acredito que o PROLESTE continua sendo um projeto extremamente moderno, que deveria ser analisado com mais cuidado: naquela época, conseguíamos reunir os educadores nas escolas em torno de um objetivo coletivo. O trabalho de reflexão para nós era rotina; semanalmente, todas as escolas paravam (geralmente na sexta-feira à tarde) para discutir, coletivamente, a sua prática pedagógica. Eu dava supervisão para as coordenadoras também uma vez por semana, na DRE, e elas coordenavam os encontros semanais com os professores, nas escolas. Então, toda semana a gente sabia tudo o que estava acontecendo em cada escola. Não porque a estrutura era centralizadora, mas porque as coordenadoras tinham espaço para trocar suas experiências e refletir sobre as práticas de coordenação. Eu vivi todo esse processo de organização dos educadores e continuo acreditando ser, talvez, a única alternativa para a democratização das relações internas na escola. Neste sentido, o PROLESTE foi um dos inspiradores da proposta do Ciclo Básico, implantado na rede estadual, em 1984, pela CENP da Secretaria Estadual de Educação: tentou incorporar a idéia de supervisão constante e de avaliação contínua do aluno. No entanto, apesar da boa vontade, houve muitos problemas porque não tiveram o cuidado de preparar os gestores do processo. Lá, em Mogi, deu certo porque, antes de pensar nos professores, nós formamos um grupo inicial de coordenadores pedagógicos e, através deles, nós construímos a rede, ou seja, o projeto cresceu gradualmente, com tempo para a formação dos coordenadores pedagógicos: iniciou em três escolas e, quatro anos mais tarde, estava em toda a rede estadual da região de Mogi. Mas, por outro lado, após esse período, o PROLESTE começou a ser muito visado, politicamente falando. Além disso, muitos educadores pressionavam para entrar na equipe... Enfim, foi difícil manter as diretrizes do projeto. Quando o projeto terminou (eu já não estava na coordenação), todos os coordenadores do PROLESTE foram contratados, como coordenadores, por escolas particulares da região. Obviamente porque tinham desenvolvido o know-how de coordenação na rede pública, ou seja, no PROLESTE.

Ana: Você deu também uma assessoria na Secretaria Estadual de Educação, não é?

Sérgio Leite: Eu estive na Secretaria como membro assessor da CEI (Coordenadoria de Ensino do Interior), que é um órgão do segundo escalão. Durante 3 anos (1996-1998), acompanhei o trabalho da rede pública no Estado. Foi interessante, primeiro para conhecer a dificuldade do trabalho de uma Secretaria de Educação; eu não conhecia a dimensão dos problemas políticos existentes, inclusive internamente, nas relações entre os diferentes órgãos da própria Secretaria. Mas tínhamos um grupo de assessores bastante comprometido com a questão do ensino público, o que possibilitou desenvolver importantes projetos na rede do interior. Em segundo lugar, foi interessante poder acompanhar de perto o que ocorre na rede, através do contato com as Delegacias de Ensino. Entretanto, após as eleições, o grupo gestor que assumiu o segundo governo Covas no Estado de São Paulo não deu continuidade aos projetos até então desenvolvidos, embora fosse do mesmo partido. Isto ilustra as dificuldades políticas para o desenvolvimento de um trabalho sério e comprometido, através da rede estadual de ensino.

Ana: Você realizou também um trabalho no MEC...

Sérgio Leite: Na época em que o MEC estava querendo definir um projeto de alfabetização nacional, participei de uma Comissão, mas que teve uma ação muito limitada. Isto foi em 1989. O relevante dessa história era o alto nível dessa comissão, formada com educadores como Paulo Freire e Magda Soares.

Ana: Sérgio, eu conheci você em 1977, quando você foi dar um curso sobre alfabetização, eu era aluna de Psicologia, e havia uma classe lotada com 
discentes de Pedagogia e Psicologia, mas você trabalhava a alfabetização dentro de uma outra abordagem, diferente do que você trabalha hoje. Como é que foi essa sua mudança de olhar, o que influenciou você?

Sérgio Leite: Tomando como referência o modelo do PROLESTE, a proposta pedagógica da alfabetização mudou; o que não mudou foi a concepção de projeto com que atuávamos, principalmente a forma de organização das pessoas. Mas do ponto de vista pedagógico, é claro, houve muitas influências. Acredito que a primeira grande influência foram as idéias de Paulo Freire, porque o PROLESTE tinha uma proposta pedagógica baseada na silabação, a partir de palavraschave conhecidas pelas crianças. Utilizamos muito a sugestão freireana na escolha da palavra-chave com a característica de uma palavra geradora. Mas aí, vieram também outras contribuições, inspiradas na teoria construtivista, na abordagem sociointeracionista e na lingüística. Mas o mais importante deste processo foi o fato de termos acompanhado este caminhar histórico de revisão da concepção da escrita. Penso que isto não foi em virtude de uma teoria em particular, mas a todo o processo de mudanças sociais e econômicas, numa sociedade marcadamente grafocêntrica, exigindo um modelo de alfabetização que respondesse mais às necessidades sociais de um novo momento. Nós evoluímos de um modelo tradicional, em que a escrita era vista como um mero código da linguagem oral, para uma concepção de escrita entendida como um sistema simbólico, cuja função é determinada pelos usos sociais de um grupo ou da sociedade.

Ana: O que marcou também sua trajetória profissional a partir do trabalho que realizou em Mogi?

Sérgio Leite: Com a redemocratização, o que houve no país refletiu também em Mogi, porque o dono da Universidade, à época, era ligado à ditadura militar. Essa situação causava grande insegurança além de constantes crises internas na UMC, envolvendo, principalmente o pessoal da Psicologia. Então eu tive que buscar outras alternativas profissionais. Fui trabalhar durante 6 anos em uma grande faculdade particular de São Paulo, ministrando aulas de PEPA (Psicologia Escolar e Problemas da Aprendizagem) e supervisão de estágios em Psicologia Escolar, no 5o ano. Em São Paulo, tentamos organizar um esquema semelhante ao de Mogi, só que agora era na 14를 (Delegacia de Ensino): curso para professores, atendimento às escolas, etc. Entretanto, esta faculdade possibilitou uma experiência extremamente aversiva pra mim, porque ali havia um conflito político-ideológico interno muito sério entre a direção e parte do corpo docente. Apesar de ter um bom corpo docente, com uma boa parcela comprometida com o processo de mudanças sociais, à medida que iam se formando as novas turmas, esses professores iam sendo substituídos, freqüentemente, por ex-alunos. Foi o que aconteceu comigo: eu me doutorei e, no ano seguinte, me mandaram embora; no meu lugar, colocaram uma ex-aluna minha, ganhando, provavelmente, menos do que eu ganhava. Mas aquela também foi uma época em que aprendi que é possível, mesmo numa escola particular, fazer um bom trabalho, desde que se garantam algumas condições básicas. Mas no caso da faculdade da qual fui expulso, eu entrei na justiça trabalhista e ganhei todo o processo, que durou longos dez anos. Acho que sou o único caso na Psicologia de um professor que teve uma vitória judicial completa contra uma poderosa instituição de ensino.

\section{Ana: Depois desta faculdade, para onde você foi?}

Sérgio Leite: Entrei na fase das universidades públicas. Em 1982, eu fui para Assis, na UNESP, onde passei um ano. Em 1983, eu entrei no Instituto de Psicologia da USP e na Faculdade de Educação da UNICAMP, simultaneamente, trabalhando nas duas Universidades em tempo parcial. Aí eu tive que tomar uma decisão porque as duas Universidades me pressionaram: eu tinha que fazer uma opção, para ficar em uma delas em tempo integral. Aí foi muito difícil, uma das decisões mais complicadas da minha vida. Mas eu já estava mais comprometido com a Educação e achava que tinha que aprofundar meu trabalho com a formação de professores, atuando na intersecção com a Psicologia. Fiquei com a UNICAMP.

Ana: Sérgio, na Faculdade de Educação da UNICAMP, você também ocupou cargos administrativos, não é?

Sérgio Leite: É, eu passei por vários deles: fui Chefe de Departamento durante duas gestões, trabalhei 10 anos na Congregação da Faculdade de Educação, participei de todas as principais comissões, atuei e ainda atuo como assessor junto à pró-Reitoria de Extensão. A partir de 
1996, eu passei a atuar mais em projetos da UNICAMP ligados à formação de professores. Também atuei, durante 5 anos, de 1989 a 1994, junto à rede estadual, em um grande projeto conveniado. Neste trabalho, eu coordenei, durante os 5 últimos anos da DRE (Divisão Regional de Ensino) de Campinas, um projeto de alfabetização para toda a DRE, com uma equipe excelente de profissionais, ${ }^{4}$ que só foi interrompido porque as DREs foram extintas, em virtude de uma reforma na estrutura da Secretaria de Educação. Aliás, a partir da minha entrada na UNICAMP, em 1984, eu participei de todos os grandes projetos em que a universidade teve envolvimento com a rede, seja como docente, seja como coordenador. Neste caso, foi muito importante participar da coordenação do PEC (Programa de Educação Continuada) UNICAMP/Secretaria de Educação, de 1996 a 1998, como assessor da Pró-Reitoria de Extensão. Coordenar o trabalho de quase trinta projetos, envolvendo praticamente todos os setores da universidade e atingindo mais de 5.000 educadores do ensino público da região, foi uma das mais ricas experiências vivenciadas por mim.

\section{Ana: Mais do que o PROLESTE? Houve outras experiências relevantes?}

Sérgio Leite: Foi um outro momento: o PEC era aberto para todas as áreas, desde Matemática, Saúde, Química, Física, e a equipe de coordenação tinha a tarefa de organizar os projetos, reunir o pessoal, instrumentalizar, garantir uma diretriz básica, acompanhar passo a passo e avaliar todo o projeto. Optamos por uma avaliação contínua: em cada fim de período do PEC, coletávamos dados, nos reuníamos e discutíamos com cada responsável. No início, as pessoas não concordavam com a avaliação, mas quando você monta uma proposta adequada, eles entendem, porque você usa a avaliação como instrumento para auxiliar e aprimorar o processo e não para prejudicar alguém ou criar tensões ou desconforto para os participantes. Mais recentemente surgiu a proposta do PROESF (Programa Especial de Formação de Professores em Exercício), criado em 2001 e implantado em 2002, na Faculdade de Educação. ${ }^{5}$ Eu participei da comissão que o criou. Este programa se inicia em um outro momento, mais recente e desafiador, porque significou planejar um curso de Pedagogia para quem já está na prática docente, já tem uma experiência. Então, tivemos que rever toda a nossa base teórica, assumindo que a prática de sala de aula do professor deve ser a base do programa, ou seja, esta tem que ser a linha do trabalho pedagógico desenvolvido em cada disciplina do plano curricular do PROESF. Atualmente, estamos nos preparando para receber a $3^{3}$ turma de 400 professores, perfazendo um total de 1.200 atendidos, o que corresponde a mais do que três vezes o número de alunos do curso regular de Pedagogia. Sobre isto, acredito que o futuro da Faculdade de Educação está muito relacionado com o desenvolvimento de projetos especiais diferenciados, como o PROESF, que está nos possibilitando trabalhar na articulação de todo o processo de educação continuada com os municípios da Região Metropolitana de Campinas. Nós estamos, atualmente, com um grupo de trabalho, envolvendo representantes de sete Secretarias de Educação, cuja tarefa é propor um projeto de educação continuada para os 19 municípios da RMC, no qual certamente a Faculdade de Educação terá um papel central.

\section{Ana: O que mais diferencia o PROESF?}

Sérgio Leite: Nós selecionamos 62 professores pedagogos das redes de ensino, dos 19 municípios da Região Metropolitana de Campinas, e ficamos durante o 1을 semestre de 2002 com eles, aqui na UNICAMP, em tempo integral, preparando-os para atuarem no Projeto, que foi iniciado no $2^{\circ}$ semestre de 2002, como APs (Assistentes Pedagógicos). Esta preparação se deu através de um curso de especialização, no qual os APs foram organizados de acordo com os três módulos do curso. A partir da implantação do PROESF, grupos de cinco APs passaram a trabalhar com cada professor da UNICAMP, responsável por uma área do plano curricular do PROESF. Ocorrem, a partir daí, encontros de estudo quinzenais do professor responsável com seu grupo de APs. Durante o período em que a disciplina está sendo ministrada, o trabalho fica centrado na supervisão semanal das atividades dos APs em sala de aula. Durante o período em que o grupo não está em atividade, os encontros são direcionados para aprofundamento dos estudos e supervisão dos projetos de pesquisa dos APs.

\section{Ana: Como foi o seu percurso de pesquisador?}

Sérgio Leite: A base do meu trabalho sempre foi a alfabetização e, a partir dos anos noventa, minhas publicações também têm versado sobre letramento. Neste período, o que ocorreu comigo foi semelhante à história de vários colegas: o encontro com as idéias de Vygotsky. O meu foi aqui na UNICAMP, através do 
contato com vários grupos de pesquisa, com destaque para o GPPL (Grupo de Pesquisa Pensamento e Linguagem). A partir daí, tenho estudado esta vertente. Portanto, este foi, de forma geral, o meu trajeto na Psicologia: alguém que vem da análise comportamental, porém marcado por algumas concepções marxistas, sempre envolvido com questões sociais, principalmente as educacionais, e o encontro com a abordagem históricocultural - isto tem sido estimulante! E aí, eu acho que a própria abordagem teórica me levou a questões que nunca havia me colocado de uma forma mais forte, como, por exemplo, a questão da subjetividade. Eu acho que este é um tema que eu devo à teoria vygotskyana e a vários orientandos que me estimularam a estudá-lo. Esta teoria também me levou a pensar na questão da leitura e da escrita, não só como um desafio pedagógico, mas olhando para o sujeito - como é que as pessoas se constituem como leitores e produtores de textos - e foi por este caminho que eu acabei abraçando o tema que estou estudando hoje, que é a questão da afetividade em sala de aula. Olhamos para este objeto não como um desafio educacional, que a escola tem que assumir como objetivo educacional, mas do ponto de vista da prática pedagógica; nosso olhar, no momento, está no professor, na relação dele com o aluno em sala de aula. Nosso pressuposto central é a idéia de que a relação que se estabelece entre o sujeito e o objeto de conhecimento depende da qualidade da história de mediação, e esta relação é essencialmente afetiva. Mas, quando falamos isto, nós não estamos falando de algo mágico, mas de mediações concretas que ocorrem em sala de aula, no caso, as práticas pedagógicas. Conseguimos identificar, pelo menos cinco decisões assumidas pelo professor, ao planejar o ensino, que têm, inevitavelmente, implicações afetivas na futura relação que vai se estabelecer entre o aluno e o objeto do conhecimento em questão: a escolha dos objetivos de ensino, a decisão sobre o ponto de partida no ensino, a organização dos conteúdos, a escolha dos procedimentos de ensino e a escolha dos procedimentos de avaliação, ou seja, nós estamos trabalhando com a idéia de que as decisões que o professor toma quando planeja um curso, os efeitos dessas decisões são marcadamente afetivos e não só cognitivos, são decisões que vão determinar profundamente as histórias de relações que se estabelecem entre os alunos e os objetos de conhecimento. E a gente está na fase de mapear isso. No ano passado, a ênfase foi no "professor inesquecível", com o levantamento de histórias incríveis de alunos que passaram por professores que mudaram as suas vidas. São coisas que nós temos que conhecer. Agora, a gente está afunilando o olhar para estudar essas relações.

\section{Ana: A sua trajetória profissional também foi marcada pela relação com as entidades de classe. Fale um pouco disto... \\ Sérgio Leite: A minha história com entidades de} classe é muito antiga, o meu envolvimento vem desde o curso secundário, através da UCES - União Campineira de Estudantes Secundaristas, onde eu militei. Em 1964, eu era vice-presidente e só não fui preso porque era menor e por ter contado com a ajuda de muitos "anjos da guarda"... A UCES foi, para mim, uma grande escola: o movimento estudantil secundário de Campinas pré64, de 58 a 64, foi uma das coisas mais marcantes que ocorreram na minha vida e na de inúmeros colegas e amigos; foi, na época, o movimento social mais forte que teve aqui em Campinas, e era dos secundaristas. Havia, no meio estudantil, a constituição de um processo de conscientização e organização, desenvolvido por vários movimentos, que poderíamos chamar de esquerda, e este grupo foi a base do movimento estudantil em Campinas. Mais tarde, já formado em Psicologia, no início da redemocratização, no fim dos anos setenta, começou em São Paulo, um movimento de oposição à diretoria do Sindicato dos Psicólogos, que foi a base para formação de uma chapa que ganhou no Sindicato, tendo como presidente a professora Odete de Godoy Pinheiro. Logo em seguida, depois de uns dois anos, veio a chapa do CRP (Conselho Regional de Psicologia), tendo como presidente o professor Luis Otávio de Seixa Queiroz... Eu tive o privilégio de participar de todo esse processo.

\section{Ana: o CRP já existia?}

Sérgio Leite: Já, mas estava na mão de um pessoal mais conservador, ou seja, o CRP ainda estava preso a uma concepção conservadora de entidade profissional. Então, houve também a articulação de um grupo para assumir o CRP, sendo que eu e a Ivone Khoury fizemos a ponte entre o Sindicato e o CRP, permanecendo nas duas entidades. Ressalte-se que, de início, o CRP era visto com desconfiança: afinal foi um produto da ditadura. Assim, na época, não foi tão simples porque as relações CRP/Sindicato não eram muito tranqüilas, apesar de os grupos serem mais próximos, politicamente falando. $\mathrm{E}$ 
depois, neste processo também ocorreu uma articulação nacional para assumir o Federal (Conselho Federal de Psicologia). Eu vivi ativamente toda essa fase de mudanças nas três instituições - no Sindicato de São Paulo, no CRP e no CFP. Participei da gestão no Federal que terminou em 1989, e me afastei um pouco dessas atividades. Recentemente, participei da gestão no Federal, de 1998 a 2001 e, posteriormente, participei da chapa desta última gestão do CRP de São Paulo. Portanto, nesta segunda fase de minha participação nas entidades, foram três anos no Federal e três no Regional.

\section{Ana: Como foi sua participação nestes órgãos? O que você aponta como positivo?}

Sérgio Leite: Eu sempre fui responsável pelo setor de comunicação das entidades. Já nos anos oitenta, eu cuidava do jornal do Federal; na segunda gestão, além do jornal, fui o editor da revista Psicologia: Ciência e Profissão. Hoje, eu coordeno o atual jornal do CRP, além do site da entidade. Acredito que o jornal e a revista são os meios concretos através dos quais o psicólogo recebe em casa a entidade, ou seja, o CRP chega em sua casa pelo jornal e pela revista. Além disso, a minha experiência nos anos oitenta foi muito rica na área de Educação, quando organizamos os psicólogos da área da Educação através da Comissão de Ensino e Educação Sindicato/Conselho. Começamos a reunir os psicólogos do Estado de São Paulo que trabalhavam com educação, e também começamos a reunir os professores que davam aula de Psicologia no ensino médio. Foi um período de grande avanço para os psicólogos que atuavam na área.

Ana: Para você, qual é o papel, hoje, das entidades de classe?

Sérgio Leite: Felizmente houve a redemocratização do país, e temos hoje uma quantidade enorme de entidades nacionais; praticamente em cada área de atuação há uma entidade nacional organizada. O Fórum de Entidades congrega mais de 15 entidades nacionais, científicas e profissionais, que são consideradas importantes, ou seja, criamos uma forma de organização exemplar para a Psicologia no Brasil. Em função disto,

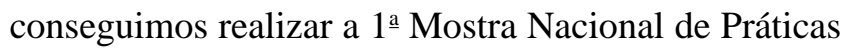
em Psicologia, em 2000, reunindo trabalhos caracterizados pelo compromisso social Fizemos, também, o Primeiro Congresso Psicologia: Ciência e Profissão, em 2002, com quase 10.000 participantes e agora já estamos começando a planejar o de 2006, com uma previsão de participação de 15 mil pessoas, novamente em São Paulo. Atualmente, a linha política do Conselho é de uma entidade para cuidar da profissão. Cuidar da qualidade dos serviços que prestamos à população, mas numa perspectiva diferente. Nosso olhar está direcionado para os efeitos da ação profissional dos psicólogos na sociedade como um todo, na perspectiva da justiça e do compromisso social. Não tem sentido você continuar insistindo nas práticas tradicionais... Temos o projeto do Banco Social, que é uma tentativa de criar espaço nos órgãos públicos e dizer: nós somos capazes de fazer outras coisas socialmente relevantes!. Enfim, quebrar aquele estereótipo de que só fazemos terapia.

Ana: Esta idéia dos testes psicológicos também vem daí?

Sérgio Leite: A idéia do aprimoramento dos testes psicológicos faz parte dessa perspectiva de cuidar da profissão. Porque o cuidar toma como referência a qualidade do serviço oferecido para a população. Portanto, não tem sentido o profissional usar instrumentos que não estão adequados para aquilo a que se propõem. É a mesma coisa se uma farmácia vendesse um remédio vencido. É óbvio que isso envolve interesses econômicos e empresariais muito fortes. Mas penso que houve um salto político qualitativo em função deste processo.

\section{Ana: E a ABRAPEE?}

Sérgio Leite: Acredito que ela enfrenta um momento em que o trabalho dos psicólogos na educação e nos órgãos públicos sofre um refluxo. Isto cria uma condição que a ABRAPEE deveria, estrategicamente, equacionar e lidar. Nós não conseguimos manter o nível organizativo iniciado nos anos oitenta na área da Psicologia Escolar. Nos anos noventa, houve, literalmente, um retrocesso na área de Psicologia Escolar. Por quê? Penso que, em parte, porque houve uma ênfase na área de saúde. Se você pegar os dados das áreas de atuação do psicólogo, nos últimos 20 anos, aparece com força o crescimento da atuação na área de saúde. Foi a novidade da última década: na Saúde, hoje, concentramse $7 \%$ ou $8 \%$ da categoria, o que é um índice respeitável, considerando-se que, há duas ou três décadas esse índice era quase zero... No entanto, com a área de Escolar isto não ocorreu; penso que houve até uma diminuição da atuação dos psicólogos na área. Se você analisar os 
serviços de Psicologia Escolar em algumas prefeituras, muitos foram deslocados para a Saúde. Houve todo um movimento que precisa ser mais estudado para que seja possível entender o fato, mas concretamente, houve uma diminuição da presença de psicólogos nas instituições educacionais, ou, como alguns defendem, não houve um aumento proporcional à demanda. Isto não quer dizer que não haja psicólogos trabalhando na área de Educação. Observa-se que nos Congressos da ABRAPEE tem havido um bom número de profissionais participando. Recentemente, a gente tentou, através do Conselho, reunir experiências realizadas em municípios, e foi difícil de achar. E quem desenvolve não se sente confortável para expor o trabalho. Num raio de 100 a 200km de São Paulo, nós conseguimos encontrar uns 2 ou 3 municípios e, assim mesmo, eles estão com receio de divulgar, por razões até compreensíveis. Mas uma outra questão que merece destaque é que, na minha opinião, os psicólogos, exceto alguns grupos universitários e trabalhos conhecidos, sempre tiveram dificuldade em romper com os modelos teóricos tradicionais, de forma a desenvolver práticas que atendam efetivamente às demandas para a construção de uma escola democrática. Como exemplo, cito a grande influência que o modelo médico ainda exerce na formação e atuação dos psicólogos. Considero tal modelo absolutamente incompatível com uma prática profissional transformadora, na área da Educação.

\section{Ana: Isto, de alguma forma, não está também ligado à militância na Saúde?}

Sérgio Leite: Pode estar. Na Saúde Mental, por exemplo, existe um forte movimento que extrapolou os âmbitos da Psicologia. Mas isto não exclui o fato de que os psicólogos ainda precisam rever a sua ação na área escolar. Há muito a ser feito que não se restringe a cuidar de "crianças-problema". Por exemplo, na Universidade, estamos trabalhando com a formação de professores, tentando mostrar que a Psicologia tem um conhecimento relevante para o dia-a-dia na sala de aula. Podemos direcionar esse conhecimento para o planejamento da ação educacional dos educadores na escola.

Ana: Houve uma divisão entre as várias entidades? Isto ocorreu com a SBP (Sociedade Brasileira de Psicologia)?

Sérgio Leite: À medida que a profissão cresce, complexificam-se suas formas de organização. Penso que a SBP tem uma marca: ficou sendo conhecida mais como um reduto do pessoal de Psicologia Experimental. Eu sei que não é real, mas ficou conhecida assim. Também penso que a Reunião Anual da SBP demorou pra sair de Ribeirão Preto/SP, do mesmo modo que e a entidade demorou para perceber a diversidade que há muito já caracterizava a Psicologia como ciência e profissão. Agora, sem dúvida, é inegável o papel histórico que a SBP desempenhou na problematização e organização da categoria e da nossa profissão. No entanto, penso que o que acontece em uma entidade é o reflexo dos tipos de conflitos que ocorrem no seu interior e como eles são internamente administrados pelos grupos que a compõem. Por outro lado, julgo que um dos grandes avanços organizativos que ocorreram na Psicologia Brasileira foi a criação do Fórum de Entidades Nacionais, do qual a SBP se afastou por divergências políticas, na época da discussão das diretrizes curriculares. Acho fundamental que a SBP volte a participar do Fórum, que é o espaço que vem se constituindo como o lócus de discussão das grandes questões da Psicologia, sem que se interfira na especificidade do trabalho de cada entidade. Além disso, o Fórum organizará eventos importantes, como o próximo Congresso Ciência e Profissão, em 2006, do qual a SBP deveria participar, inclusive para se fortalecer. Trata-se, afinal, da maior reunião da Psicologia Brasileira.

\section{Ana: Como você vê a relação da Psicologia com} a Educação?

Sérgio Leite: Há uns 15 anos, escrevi um artigo apontando que a grande tarefa nossa, como psicólogos, é possibilitar aos profissionais que atuam na área da Educação o acesso a este conhecimento, para poderem realizar o seu trabalho nas escolas e instituições educacionais. Eu continuo defendendo esta posição ardentemente e cada vez mais convencido dela. Acho que nós deveríamos, de vez, assumir esta bandeira. Minha preocupação é colocar o conhecimento da Psicóloga disponível aos professores e educadores, visando ao planejamento de suas ações. No entanto, tradicionalmente, a Psicologia, como profissão, tem sido direcionada para cuidar dos produtos da ação educacional inadequada e, principalmente, injusta para a maioria marginalizada da população. Na minha opinião, esta é a principal razão pela qual nós perdemos muito espaço na área escolar. Temos tido dificuldade de direcionar o conhecimento psicológico para uma prática que colabore com o processo de 
democratização da escola. Isto parece meio contraditório, mas eu defendo que o conhecimento psicológico é fundamental para o desenvolvimento do trabalho dos educadores nas escolas.

Ana: Então, eles precisam das contribuições da Psicologia e não das contribuições do psicólogo? Por que você não defende o psicólogo na escola?

Sérgio Leite: Porque eu acho que o acesso ao conhecimento psicológico, pelos educadores das redes de ensino, pode não ser mediado, única e exclusivamente, pelo psicólogo. Se você me perguntar qual é o lugar do psicólogo como um profissional no serviço público, talvez eu diga que é na Saúde mesmo. Mas, por outro lado, o que eu vejo em termos de produção científica é que existe um conhecimento em nossa área que é fundamental para o trabalho do professor em sala de aula. Vários orientandos meus e de outros colegas fizeram excelentes pesquisas sobre o tema. Só que para isso é preciso que o psicólogo também tenha acesso a este conhecimento e saiba administrá-lo na sua prática profissional. E isto freqüentemente não ocorre. Por exemplo, acerca do planejamento educacional: o psicólogo não tem uma formação pedagógica mínima para entender o que isto significa... Eu passei cinco anos na Faculdade, sem nunca ter estudado questões sobre planejamento educacional. Eu só fui entender este vínculo muito mais tarde, quando comecei a descobrir o que o professor faz em sala de aula e perceber que o que eu estudo tem a ver com o que ele faz. Por outro lado, quais são as faculdades que trabalham com esta perspectiva? Os planos curriculares da formação dos psicólogos incluem questões deste tipo? Como agravante, existe ainda uma demanda forte, baseada em concepções conservadoras, centradas no modelo médico tradicional, tentando, teimosamente, buscar nos alunos as causas das mazelas educacionais. Tal posição acaba preservando a atual estrutura e funcionamento das instituições escolares. Nesta situação, vários colegas profissionais acabam sucumbindo às pressões, pois muitas vezes o seu emprego está em jogo. Assim, as possibilidades de atuação do psicólogo na Educação, no meu entender, dependem de sua adequada formação e envolvimento com as questões educacionais. Isto parece ser condição para que ele socialize o saber psicológico na perspectiva da construção de uma escola democrática. Neste sentido, tenho observado que somente aquelas faculdades ou instituições que têm grupos de profissionais organizados na área, têm conseguido romper com o modelo tradicional e anacrônico e, portanto, avançar, ou seja, eles mostram que a possibilidade de construção de novos modelos e alternativas de atuação não é tarefa para profissionais isolados. É um empreendimento que somente terá sucesso através do trabalho coletivo. Eu acho que este é o nosso caminho. O nosso desafio histórico... 